\title{
EI XXXII Congreso Eucarístico Internacional de 1934 en las páginas \\ de la revista Para $\mathrm{Ti}$
}

\author{
Alicia Florián* \\ Silvana Fogliato ${ }^{* *}$
}

Fecha de Recepción: 20 de Abril de 2020

Fecha de Aceptación: 05 de Junio de 2020

DOI: https://doi.org/10.46553/RGES.56.2020.p.12-35

\section{Resumen}

Durante cuatro días del mes de octubre del año 1934 se celebró el XXXII Congreso Eucarístico Internacional organizado en honor al Jesús Sacramentado. Por primera vez, se distinguía al continente sudamericano para la realización del encuentro religioso eligiendo a Buenos Aires como sede, lo cual fue considerado como un honor para la iglesia católica del país. El Congreso desató una fiebre eucarística y demostró el fervor popular cristiano de la sociedad argentina luego de décadas de avance laicista desde el Estado y las instituciones civiles. Este evento, además, manifestó la presión de las masas populares católicas por ocupar espacios cada vez más prominentes en la vida pública y social, hecho que se manifestó en la adhesión masiva a cada uno de los actos que se brindaron para esta ocasión en todo el país.

La magnitud del Congreso se vio reflejada por los medios gráficos de comunicación que cada día ampliaban más su campo de penetración hacia los diferentes sectores letrados. Entre las publicaciones masivas ya consolidadas en la Argentina de los años treinta del siglo XX, el semanario femenino Para Ti de Editorial Atlántida representaba un exponente de la lectura femenina de los sectores urbanos medios y populares en ascenso. El mismo se hace eco, desde sus secciones dedicadas a la actualidad, del desarrollo del Congreso Eucarístico y deja ver el rol de la mujer en esta manifestación religiosa.

Palabras clave: Congreso; periodismo; catolicismo; literatura femenina

\begin{abstract}
For four days in October, 1934, The 32 ${ }^{\text {nd }}$ International Eucharistic Congress was celebrated and organized in honor of Jesus in the Bless Sacrament. For the first time, the South American continent was distinguished to hold the religious encounter, choosing Buenos Aires as venue. This was considered an honor by the local Catholic Church. The Congress caused an eucharistic fever and it demonstrated the popular Christian fervour of the Argentinian society, after decades of secularist progress from the State and the civil institutions. The event revealed the popular catholic mass pressure to occupy increasingly prominent spaces in the public and social life, fact manifested in the massive support for each Congress act throughout the country.

The magnitude of the Congress was reflected by the graphic media, which increasingly widened their field of penetration towards the different professional sectors. Among the long-standing massive publications in the 30s of the $20^{\text {th }}$ century, the weekly women's magazine Para Ti, by Editorial Atlántida, represented a sample of the women's readings of the rising middle and popular urban areas. From its sections dedicated to topical issues, the magazine covers the development of the Eucharistic Congress and it reveals the role of women in the religious manifestation.
\end{abstract}

\footnotetext{
* Instituto de Historia, Facultad de Derecho y Ciencias Sociales del Rosario, Pontificia Universidad Católica Argentina. abflorian@gmail.com

** Instituto de Historia, Facultad de Derecho y Ciencias Sociales del Rosario, Pontificia Universidad Católica Argentina.silvanafogliato@gmail.com
} 
Key words: Congress; Journalism; Catholicism; Female Literature

\section{Introducción}

La designación vaticana de la ciudad de Buenos Aires como sede del Congreso Eucarístico Internacional de 1934 ponía de manifiesto el lugar que la Argentina ocupaba en el concierto de las naciones cercanas a Europa desde fines del siglo XIX. Asimismo, dada la dura situación que atravesaba el país a mediados de la década, tras la crisis económica e institucional abierta en 1930, desde distintos sectores se creía que esta era la oportunidad para hacer ver al mundo que el país caminaba en vías de fortalecimiento económico y cultural, ofreciendo una imagen de prosperidad recuperada.

Así, con una Carta Pastoral Colectiva emitida en 1933, los obispos argentinos informaron y presentaron la realización futura del Congreso Eucarístico Internacional a desarrollarse en el país al año siguiente. En él se referían a la delicada situación internacional, y en particular, al contexto de la Argentina. Afirmaban que, a pesar de la preocupación por la ola laica y agnóstica que parecía envolver el mundo y a la sociedad nacional: "Nuestra Madre la Iglesia, al contemplar, en estos últimos tiempos, la ola de frío espiritual que ha invadido al mundo, con la difusión del materialismo, laicismo, egoísmo e indiferentismo, ha renovado, la antigua invitación de Santo Tomás a las lenguas de los fieles para que (...) caliente el ambiente social con las vibraciones de su cántico triunfal a Jesucristo Sacramentado (...)”. ${ }^{1}$

En otro orden de cosas, la Carta Pastoral Colectiva de 1933 instaba a comenzar ejercicios espirituales y misiones, a la asistencia sacramental de los fieles y a incentivar la cultura religiosa desde las cátedras seminaristas y desde los púlpitos de cada templo del país, para reforzar con nuevas adhesiones y vigorizar con nuevo entusiasmo las obras eucarísticas, tomando parte en los Congresos Regionales, y en solemnidades locales que tuvieran a cargo los Comités Diocesanos y Parroquiales. En suma, se fomentaba el apoyo a la labor preparatoria que recaía en las Comisiones Nacionales del futuro Congreso Internacional.

La preparación del Congreso alentaba -además de la movilización de las parroquias-a los Círculos Católicos de Obreros, como también a la contribución de las conferencias vicentinas y de los colegios católicos. De esta manera, una serie de Congresos a microescala, celebrados en parroquias, pueblos y ciudades a lo largo y a lo ancho del país, preparó el clima para el evento del año siguiente. El entusiasmo despertado por estos adelantos, que se venían

\footnotetext{
1 “Carta Pastoral Colectiva de los Excmos. y Rvmos. Sres. Obispos Argentinos sobre el Congreso Eucarístico Internacional" en I Congreso Eucarístico de la Diócesis de Santa Fe, Publicación Oficial de la Junta Diocesana de Santa Fe (Zona Sud), Rosario, 1933, pág. 181.
} 
desarrollando en las ciudades de Córdoba, Rosario y Tucumán, quedó registrado en la publicación oficial del Primer Congreso Eucarístico de la Diócesis de Santa Fe del año 1933, en las expresiones del periódico El Pueblo, con fecha del 12 de octubre, al señalarse que:

Ayer Tucumán, el jardín de la república, la vieja ciudad guardiana de nuestros tesoros patrióticos enclavada entre la quietud de su flora magnifica, contemplaba la triunfal apoteosis de la Eucaristía asombrando al país entero en el espectáculo impresionante de la Fe de sus habitantes...

Hoy, Rosario, la segunda ciudad de la República, la urbe moderna, estrepitosa, afiebrada, la ciudad palpitante de esa nerviosidad, de las fábricas, los puertos, las bolsas y los bancos, renueva el espectáculo de Tucumán, dentro de un margen distinto al de la placidez provinciana $\mathrm{y}$, por eso mismo, aún más impresionante... Rosario ha anticipado el homenaje que rendirá Buenos Aires a la Eucaristía en octubre del año próximo... ${ }^{2}$

El mismo medio, dos días después, auguraba el éxito del evento venidero: "No puede ser más optimista la impresión que han dejado los congresos realizados: para la Iglesia y para el país, por las saludables y reconfortantes enseñanzas que han de quedar grabadas muy íntimamente en las mentes y voluntades de todos los que se han puesto al contacto de ese Sol de Justicia". 3

Por otra parte, sobre la Acción Católica Argentina, creada en 1928, recaía el peso de la organización del Congreso Eucarístico. Paralelamente, se hacía notar la participación activa del grupo de intelectuales nucleado en torno a los Cursos de Cultura Católica y a la revista Criterio, tales como Tomás Casares, Atilio Dell’Oro Maini, Cesar Pico, Samuel Medrano, Monseñor Gustavo Franchesci, y el Dr. Elías Luque en representación del laicado de la iglesia rosarina. $^{4}$

Luego de una etapa de laicización, la religiosidad regresaba de la mano de los padecimientos desencadenados por la situación de crisis que atravesaba el país. ${ }^{5}$ La presencia

\footnotetext{
2 “Carta Pastoral Colectiva de los Excmos. y Rvmos. Sres. Obispos Argentinos sobre el Congreso Eucarístico Internacional”, Pág. 181.

${ }^{3}$ El Pueblo, 14 de octubre de 1933, Buenos Aires en Primer Congreso Eucarístico de la Diócesis de Santa Fe, Publicación Oficial de la Junta Diocesana de Santa Fe (Zona Sud), Rosario, Pág. 179.

${ }^{4}$ Entrevista a la Sra. Rosa Luque de Ponce, Rosario, 19 de mayo de 2004.

5 Se trataba de una revancha que la Iglesia había esperado desde el embate liberal que había impulsado la organización del Estado y la construcción de una identidad nacional en las últimas décadas del siglo XIX.
} 
de segmentos populares urbanos cada vez más dinámicos, la intelectualidad ligada al nacionalismo católico a través de las páginas de Criterio, sectores de la juventud conservadora, las Fuerzas Armadas con su presencia en la vida política institucional cercana a los nacionalismos, y también, la acción y el carisma de Monseñor Gustavo Franceschi, fueron la punta de lanza de un redescubrimiento de la fe por parte de la población, en especial, de los centros urbanos en expansión. En esta misma línea, los templos que habitualmente albergaban a una notoria mayoría femenina comenzarían a poblarse de hombres de todas las edades, gracias al influjo de la Acción Católica Argentina.

Pues bien, esta recuperación del fervor católico y de la defensa de sus valores tradicionales, coincidiría con la expansión de los movimientos totalitarios, y como barrera ante las ideologías cercanas a la extrema izquierda; además de la necesidad de fortalecer los valores considerados nacionales y tradicionales, en consonancia con la prédica del nacionalismo.

Así, durante una semana se concentraría en Buenos Aires el interés de la opinión católica nacional e internacional, la cual contó con el representante del sumo pontífice, el Cardenal Eugenio Pacelli, futuro papa Pío XII.

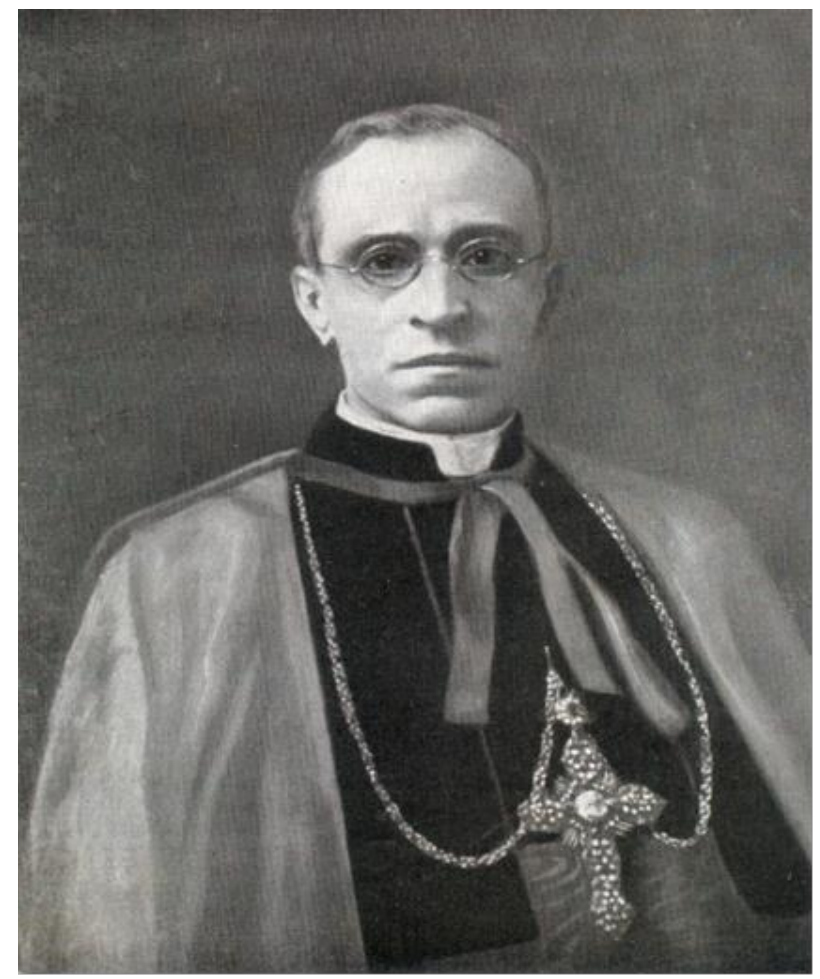

El Cardenal Monseñor Eugenio Pacelli, Secretario de Estado del Vaticano, quien invistió en el XXXII Congreso Eucarístico Internacional la representación de su santidad Pío XI.

FUENTE: Historia de Parroquias de Buenos Aires (Comisión de Investigaciones Histórico Eclesiásticas del Arzobispado de Buenos Aires www.historiaparroquias.com.ar) 


\section{"¿Cristo Vence!"}

Por fin, el día 10 de octubre de 1934 tuvo lugar la apertura del XXXII Congreso Eucarístico Internacional, en el Parque Tres de Febrero de la ciudad de Buenos Aires. El acto se desarrolló en una plataforma que circundaba a El monumento de los españoles, al que ocultaba una cruz de 35 metros de altura que se transformaría después en el emblema del Congreso. A su turno, se leyó la Bula papal por la que el cardenal Eugenio Pacelli fue investido por su santidad Pío XI del cargo de delegado. Una Hora Santa sacerdotal completaba ese primer día de fe.

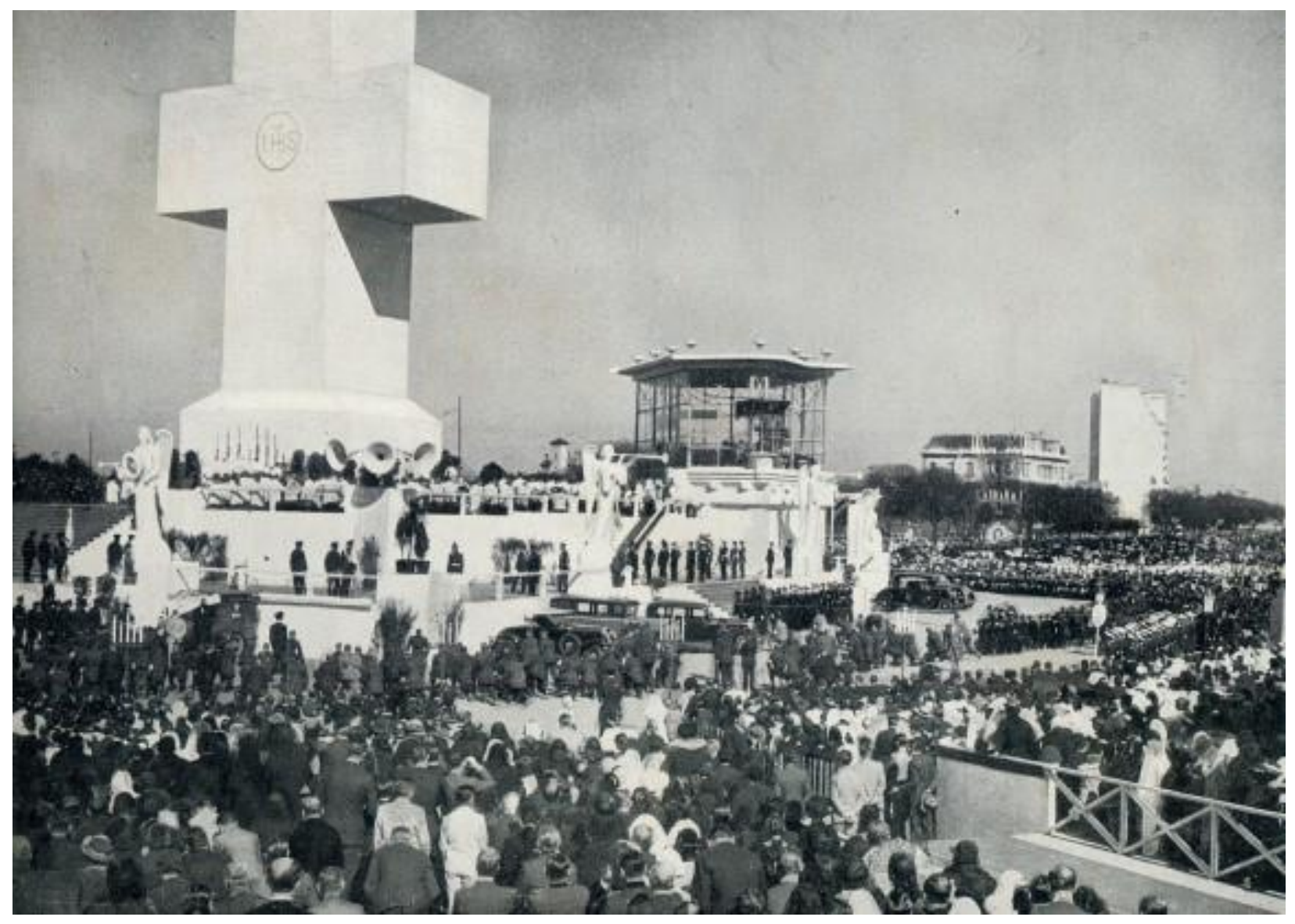

Altar Mayor, durante el oficio religioso dedicado al Ejército Argentino.

FUENTE: Historia de Parroquias de Buenos Aires (Comisión de Investigaciones Histórico Eclesiásticas del Arzobispado de Buenos Aires.

www.historiaparroquias.com.ar) 
La jornada siguiente se había destinado a los niños, y para la ocasión se reunieron en los jardines palermitanos a 107.000 menores. ${ }^{6}$ Por la tarde, se realizó la primera Asamblea General del Congreso, cuyo tema fue "Cristo, Rey de la Eucaristía y por la Eucaristía”. Más tarde, se celebró La noche de los hombres, protagonizada por miles de devotos que marcharon por una Avenida de Mayo colmada para participar en la misa que tendría lugar simultáneamente en la Plaza de Mayo. Esto dejaba a la vista que en distintos sectores sociales el espacio masculino de la fe se fortalecía y continuaba creciendo. En este sentido, la nueva catequesis sembrada por el Congreso Eucarístico apelaba, especialmente, a la evangelización de los niños con el fin de revertir la tendencia de la práctica religiosa activa, por lo general ceñida a los ámbitos femeninos.

El día 12 de octubre se conmemoraron los orígenes católicos e hispanos de la Nación Argentina, y a su vez, se celebró la fiesta de Nuestra Señora del Pilar; mientras que por la tarde tuvo lugar la segunda Asamblea General del Congreso que se refirió a "Cristo Rey en la vida católica moderna". Al día siguiente, se realizó La Jornada de la Patria dedicada a la Virgen de Luján, patrona del Congreso. Frente a la Cruz palermitana, durante la misa siete mil soldados recibieron la Eucaristía, presencia que dejaba en claro la adhesión de las Fuerzas Armadas a la fe católica y su alianza como factor de poder. Esta expresión ritual, además, tendría sus réplicas en los congresos diocesanos en el interior del país. Por la tarde de ese mismo día, se daba apertura a la tercera Asamblea General del Congreso acerca de "Cristo, hoy, en la historia de América Latina y, especialmente, en la República Argentina”.

El 14 de octubre, por último, se llevó a cabo El Día del Triunfo Eucarístico Mundial. Más de un millón de personas concurrieron a Palermo para asistir a la misa que oficiaría el legado pontificio. Al culminar, en medio de un silencio absoluto -y en un alarde de la técnica de comunicación para la época-, se oyó la voz del Sumo Pontífice que desde el Vaticano proclamaba: "Cristo Eucarístico, vive, reina e impera". Luego de la bendición papal, la multitud regresó para la procesión de Clausura. En esta jornada, también participó el presidente Agustín P. Justo, quien pondría voz al espíritu nacionalista, centrado en la adhesión a la fe de Cristo, y en especial a los valores conservadores afines a la jerarquía eclesiástica. De esta manera, empezaba a consolidarse una alianza que se haría palpable durante los años y décadas siguientes.

\footnotetext{
${ }^{6}$ Apuntes para la memoria de la Argentina Católica sobre el Congreso Eucarístico de Buenos Aires, 10 a 14 de octubre de 1934 en web: Panorama Católico Internacional. Experiencias y Tradiciones de los Congresos, 10 de octybre de 2008 .
} 
El diario El Litoral, en la edición matutina de ese mismo día destacaba la presencia de unas 700.000 personas que se habían dado cita en el espacio de Palermo, alrededor de la Gran Cruz para recibir la bendición de Su Santidad el Papa, impartida por radiotelegrafía desde el Vaticano. Igualmente, hacía notar que la organización era perfecta y merced a ella el público había podido tomar ubicación en las distintas zonas en la que estaba dividido el recinto. Asimismo, señalaba la conveniencia de haber tomado precauciones ante los peligros de la canícula. ${ }^{7}$ Más puntualmente, se observaba la notable actuación en los protocolos sanitarios del militante católico Elías Luque, destacado profesional médico de la ciudad de Rosario, a cuyo cargo se encontraba la organización del servicio de primeros auxilios, y dentro de su órbita debía dirigir al numeroso personal de la salud distribuido en los múltiples eventos religiosos. $^{8}$

En efecto, durante aquellos cuatro días, la ciudad de Buenos Aires albergó visitantes procedentes de todo el país y del extranjero. Se habló de un millón de personas, aunque no existe certeza sobre esta cifra. Verdad es que arribaron a estas tierras visitantes extranjeros con sus respectivas comitivas oficiales, tanto de países limítrofes como de Europa. De acuerdo a fuentes oficiales de la Iglesia argentina se estimaría que "en Buenos Aires en 1934 se repartieron 100.000 comuniones a niños, 400.000 a hombres y 700.000 a mujeres". ${ }^{9}$ Como corolario, las cifras indican que el evento estuvo marcado por una muy intensa práctica sacramental.

\footnotetext{
7 "Con un Acto de proporciones fantásticas se clausuraron las Asambleas del XXXII Congreso Eucarístico de Buenos Aires”, El Litoral, 14 de octubre de 1934, pág. 1.

${ }^{8}$ Fondo Documental del doctor Elías Luque, donado al Instituto de Historia de la UCA por su hija Rosa Luque de Ponce, Rosario, 2004.

9 “Congreso Eucarístico de Buenos Aires, 10 a 14 de octubre de 1934”, https://panoramacatolico.info/congresoeucaristico-de-buenos-aires-10-a-14-de-octubre-de-1934/
} 


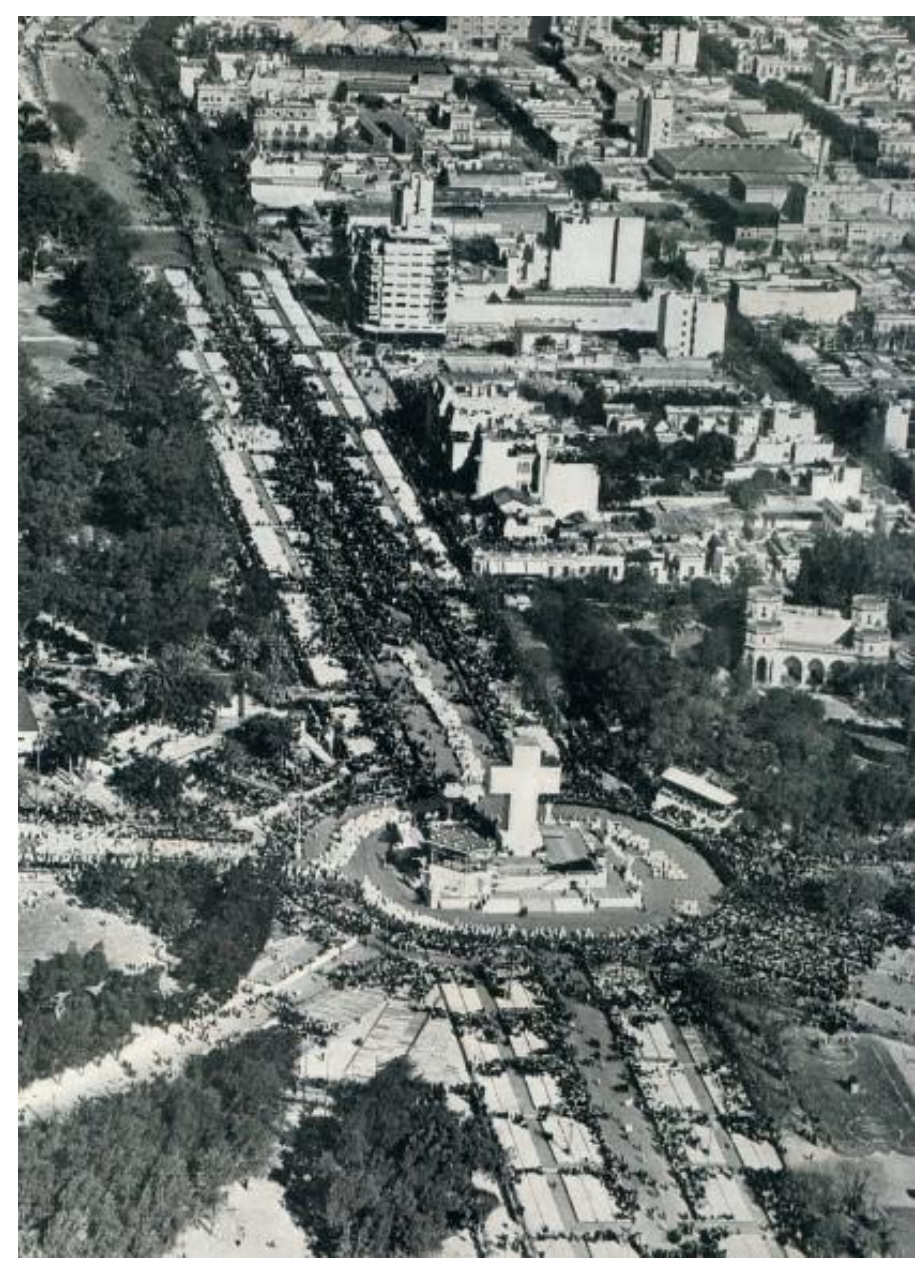

Aspecto de las calles del barrio de Palermo durante los distintos actos del Congreso el gran Monumento al iniciarse los diferentes actos. FUENTE Historia de Parroquias de Buenos Aires (Comisión de Investigaciones Histórico Eclesiásticas del Arzobispado de Buenos Aires. www.historiaparroquias.com.ar)

De esta forma, con la mirada dirigida hacia el futuro, la repercusión del Congreso iba a perpetuarse más allá de aquellas jornadas, fortaleciendo las miradas e ideas acordes al espíritu de orden nacionalista, cuya cristalización llegaría hacia fines de la década. En consonancia, el Consejo Directivo del XXXII Congreso Eucarístico Internacional propuso que la Cruz levantada para tal efecto en los bosques parlemitanos de la Capital Federal se reproduzca en el espacio urbano de la zona y se emplace una capilla a fin de que, cada 12 de octubre, allí tuviera lugar una celebración eucarística. 


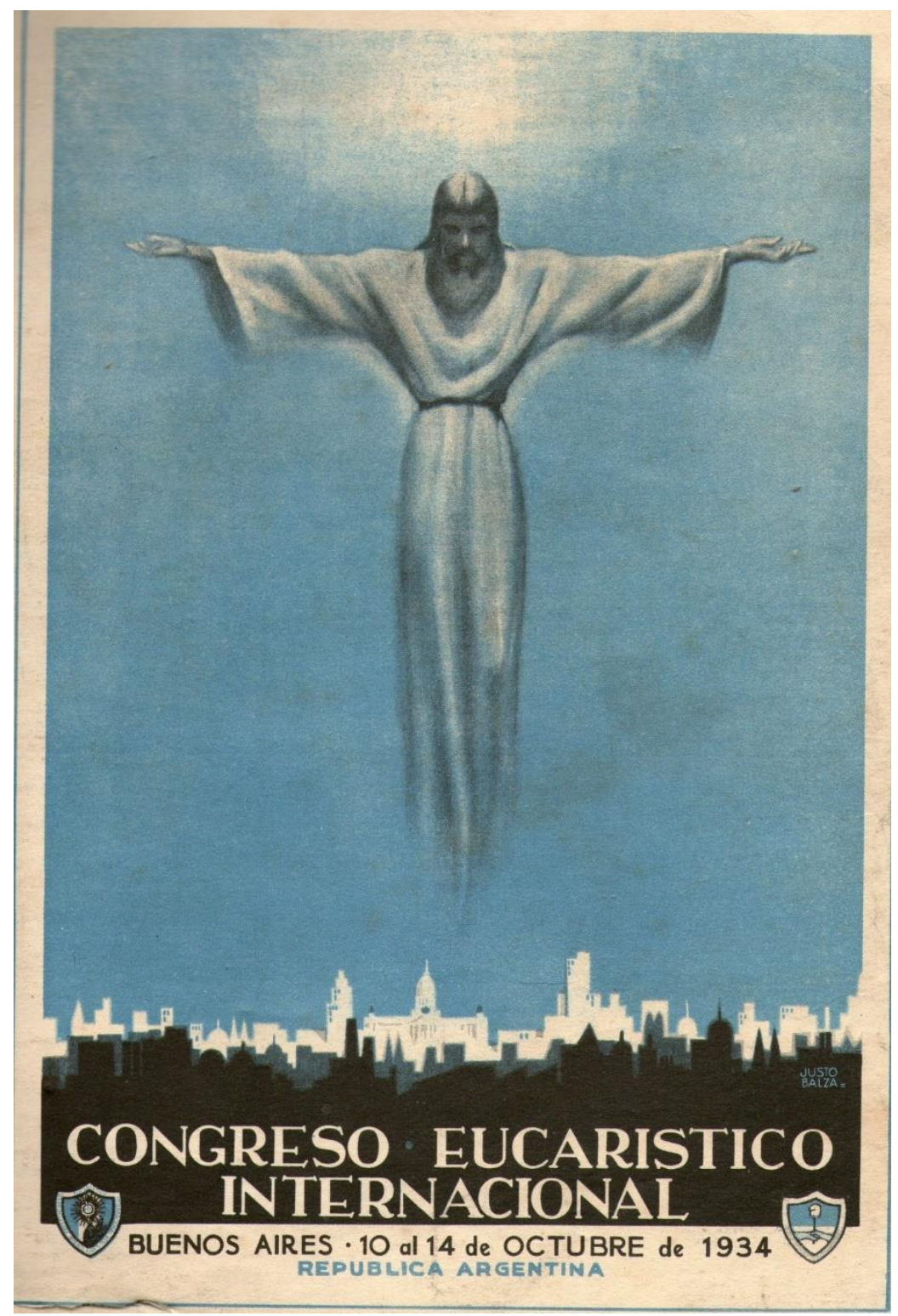

Afiche del Congreso Eucarístico Internacional que aparecía en la contratapa de la revista Para Ti edición dedicada al mencionado evento.

\section{La repercusión del Congreso en los medios. El caso de la revista Para Ti}

El gran despliegue del Congreso tuvo impacto en los medios de comunicación de la época, tanto en los diarios y semanarios nacionales más importantes como La Nación, La Razón, Caras y Caretas, como también, en los medios radiales que transmitieron las vicisitudes del evento a cada rincón del país a través de la voz del locutor Dionisio Napal, encargado de la difusión radial de las ceremonias. Los medios gráficos, por su parte, publicaron números especiales, junto a una abundante producción fotográfica que evidencia los adelantos técnicos de esos años. Si bien las cámaras cinematográficas ya habían registrado 
voces y rostros durante el Congreso de Rosario del año anterior, las tomas panorámicas pueden brindarnos una pauta de las dimensiones de este evento que movilizó a multitudes.

Así pues, uno de los semanarios gráficos que cubrió el acontecimiento religioso fue la revista Para Ti, de Editorial Atlántida. La misma, desde su primera tirada en 1922 respondía al segmento femenino de lectores que venía creciendo de la mano de las transformaciones sociales y de la ampliación de los sectores letrados urbanos. ${ }^{10}$ El semanario para la "mujer moderna" puso a las protagonistas en el centro del hogar; pues aunque expandiera el foco a los trabajos admitidos para la mujer de su tiempo, fundamentalmente atendía a la formación del ama de casa, proporcionando información sobre conceptos de higiene, salud, economía doméstica, oficios, tras el cometido de encumbrarla a guardiana de la familia y de la respetabilidad social. También, sus páginas se dedicaban a la moral femenina que dejaba atrás costumbres caducas y prejuicios risibles; impedimentos para ser la verdadera compañera del hombre. Vale decir, se ponderaban los nuevos hábitos, pero continuaba asociada al varón: la mujer moderna esbozada por Para Ti reproducía, en cierta forma, a aquella mujer tradicional. Con el correr de los años, la revista llegaría a brindar secciones destinadas a la mujer trabajadora de clase media urbana, al punto de representar para sus lectoras una caudalosa fuente sobre diferentes temas, como guía de la moda y consejera en temas sociales. ${ }^{11}$

Cabe decir que hacia mediados de la década ' 30 , los espacios de ocio de los sectores letrados urbanos, ya cristalizados desde tiempo atrás, se iban arraigando con el acceso a nuevas formas populares de divulgación gráfica. La radio y el cine aumentaban sus adeptos, pero también se expandían las novedades editoriales segmentadas según nichos etarios y temáticas. Por cierto, la industria editorial, cada vez más fuerte, ponía en manos de un público curioso y ávido, aventuras, consejos, enseñanzas, diversión, información, por unos pocos centavos que disfrutaban toda la semana. ${ }^{12}$

En el caso puntual de la revista de Constancio Vigil, sus páginas ofrecían algunas secciones fijas como "Comentarios", "Epistolario sentimental", "Mujeres de América",

\footnotetext{
${ }^{10}$ Las revistas femeninas en su mayoría ostentaban una larga trayectoria. Entre las publicaciones de mayor presencia en la época: El Hogar (Ed. Haynes, 1904-1957) y Para Ti (Ed. Atlántida, desde 1922) mantienen sus características tradicionalistas, en tanto Vosotras (Ed. Korn, aparecida en 1936) se destina a lectoras de menos recursos. Ver: Isabella Cosse, "Claudia: la revista de la mujer moderna en la Argentina de los años sesenta (1957-1973)”, Revista Mora, vol.17, N¹(2011), https://www.aacademica.org/isabella.cosse/17

${ }^{11}$ Para Ti comenzó a ser editada con un claro tinte conservador, defensora del papel femenino tradicional, impreso por el fundador de la Editorial Atlántida, Constancio Vigil. Ver: Juana Alicia D'Andrea, "Todo lo que interesa a la mujer. Para Ti y su tono moralizador durante el primer gobierno peronista (1946-1952)", en IV Congreso de Estudios sobre el peronismo (Tucumán: Facultad de Filosofía y Letras, Universidad Nacional de Tucumán, 2014), pp. 5 y 6.

${ }^{12}$ José Luis De Diego (Dir.), Editores y políticas editoriales en Argentina. 1880-2010 (Buenos Aires: Fondo de Cultura Económica, 2014).
} 
"Entre nosotras", "Para la dueña de casa" (consejos sobre economía y organización doméstica), "Modas", "Mangancha la dactilógrafa" (sección de humor), y avisos gratis generalmente destinados a pedidos u ofrecimientos de trabajos para mujeres. Además, contenía un dossier fotográfico cuyas temáticas se concentraban en los eventos públicos, la mujer y los deportes, agasajos benéficos, cine, etc.

En los albores de los años 30, Para Ti contaba con una publicación de 110 páginas. Al mismo tiempo había incrementado en forma sostenida la cantidad de ejemplares semanales y se proyectaba hacía el mercado Latinoamericano. ${ }^{13} \mathrm{Si}$ bien el semanario también trazaba pinceladas acerca de cuestiones vinculadas a la actualidad, lo hacía desde un ángulo netamente "femenino", desde sus secciones destinadas a las novedades sociales, al espectáculo, al ocio y a todo aquello que repercutiera en el cuidado de la salud, el hogar y los hijos. Por lo demás, también allí se publicitaban bienes de consumo, aunque primordialmente se dedicada a la salud y belleza, y al mantenimiento general de la casa.

En pocas palabras, Para Ti proponía artículos que no pusieran en cuestión el lugar doméstico de las mujeres de los sectores medios y populares, más aún, este patrón era apuntalado y ampliado en sus páginas. Así, la fórmula que encontró para incorporarlas a la modernización de las costumbres, sin que ello significara un cambio radical, fue la figura de mujer moderna entendida como un concepto maleable en constante transformación, según la dinámica de la modernización de la vida material y de los nuevos roles femeninos que en ciertos estratos sociales iban tomando colores definitivos. En efecto, el "modelo" de mujer que promovía se articuló en el par dicotómico moderno-tradicional. Para Ti presentaba a las mujeres modernas como mujeres actuales. Al mismo tiempo, las contraponía con representaciones del pasado. Dicho concepto se orientaba a una mujer eficaz acorde a sus tiempos, situada en el mundo real, pero sin descuidar los roles tradicionales vinculados al hogar y al matriarcado. Las publicaciones estaban destinas a quienes leían novelas, utilizaban moldes de bordado y costura, recetas de cocina: un abanico de consejos y datos que correspondían más a los intereses de mujeres tradicionales que a los de las supuestas mujeres modernas. Se apelaba, de esta manera, a los sectores medios y populares con aspiraciones de ascenso que participaban de la modernización de las primeras décadas del siglo XX. ${ }^{14}$

En definitiva, el semanario era fiel reflejo del espíritu conservador de su responsable Editorial Atlántida. El pensamiento de fuerte raigambre católica de Constancio C. Vigil

\footnotetext{
${ }^{13}$ Paula Bontempo, "Para Ti: una revista moderna para una mujer moderna, 1922-1935", Estudios Sociales, Vol. 41, No 1 (2011), p. 152.

${ }^{14}$ Paula Bontempo, Editorial Atlántida. Un continente de publicaciones, 1918-1936 (tesis doctoral, Universidad de San Andrés Buenos Aires, 2012), pp. 292 y ss.
} 
cuajaba en las líneas editoriales de Para Ti y de otras publicaciones, atribuyendo a la lectura y la ilustración en general, la posibilidad de moldear a las personas y contribuir así a la formación del ciudadano. ${ }^{15}$

Por otro lado, las grandes tiradas de las editoriales, especialmente de diarios porteños, se duplicaban en número de páginas y se lucían con fotografías cuando se cubrían eventos importantes como el Congreso Eucarístico de Buenos Aires. Sus preparativos, desarrollo y repercusiones fueron debidamente retratados por las principales publicaciones, y Editorial Atlántida no quedaba al margen en ese momento.

En ocasión del evento religioso, la redacción de Para Ti dedicaría una edición especial previa al Congreso Eucarístico en su $\mathrm{N}^{\circ}$ 648, del 9 de octubre, con una tirada récord en el periodismo argentino de 310.000 ejemplares que contaba con un total de 154 páginas para ir palpitando lo que sería el evento religioso de esos días en la ciudad. Desde la portada con el slogan Todo lo que le interesa a la mujer se anticipaba el contenido del semanario con una gran imagen de Jesús Sacramentado y en la margen inferior derecha, el escudo del Congreso Eucarístico. Además, en la contratapa se presentaba la misma figura de Cristo que había sido estampada en el folleto de difusión del Congreso Eucarístico Internacional. Desde su primera página se advertía que el número era un homenaje a Cristo Jesús en el Augusto Sacramento del Altar, apelando a la sensibilidad de sus lectoras.

\footnotetext{
${ }^{15}$ D'Andrea, Todo lo que interesa a la mujer..., p. 6.
} 


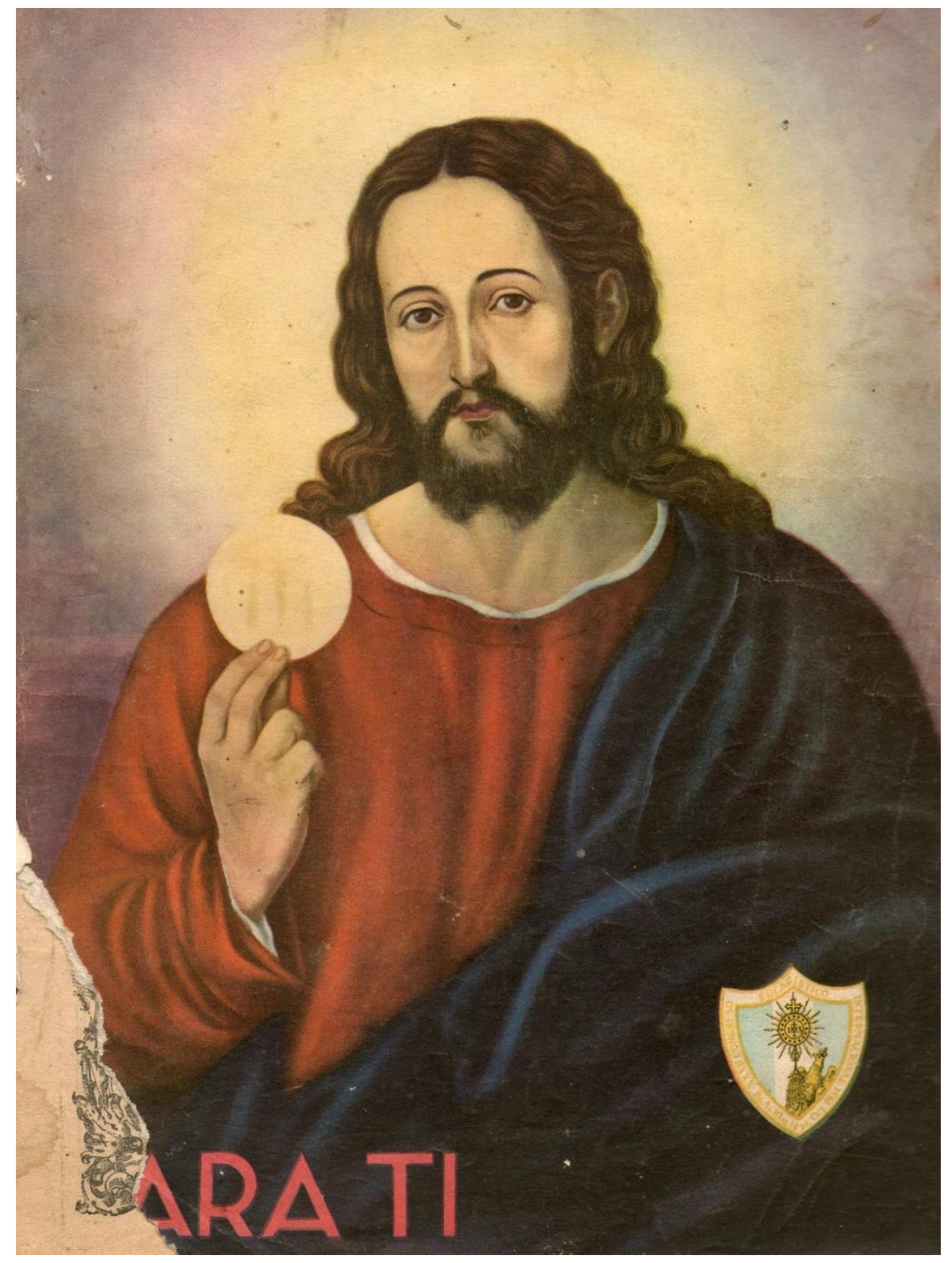

Portada de la revista Para Ti dedicada al Congreso Eucarístico Internacional de 1934.

Si nos detenemos en el sumario de ese ejemplar, allí se exhibe un número considerable de notas de distintos autores y colaboradores frecuentes de la revista, aparte de pensadores, escritores, periodistas, poetas, religiosos, y críticos que participaron especialmente en este número. Asimismo, figuran autores célebres de todos los tiempos. Entre ellos, podemos citar a Marcos Rafael Blanco Belmonte, Dominic Moore C. P., Ramiro R. de Dulanta, Armando Burguera, José Albuerne, Manuel Abril, H. Ranieri C. R. L., Beato Tomás de Kempis, P. Bourdaloue, P. Adolfo EtcharteSch. P., F. Casañas Lemos, R. de Córdoba, Cardenal Wiseman, P. Umberto Ranieri C.R.L., P. Teodoro Palacios, Azorín, entre otros. ${ }^{16}$ Queda demostrada la hondura intelectual de estos autores, ya que como vemos nos encontramos con

\footnotetext{
${ }^{16}$ Revista Para Ti, Año XIII, No 648, 9 de octubre de (1934), p.4.
} 
personalidades de la generación del '98, religiosos que ya habían participado en congresos eucarísticos anteriores, textos de Santos y Padres de la Iglesia...como también, escritores de España y de otros orígenes que encarnaban diversas posturas políticas.

En cuanto a los temas, los artículos publicados en este número especial de Para Ti giran en torno al misterio de la eucaristía, a los diferentes congresos eucarísticos, a la fe, a la letra y música de cánticos religiosos, a diferentes relatos de vida de mártires, santos, beatos y religiosos. Entre ellos, podemos mencionar: La Fe y la Eucaristía de Ángel Ll. del Rey, El adorable Sacramento de la Eucaristía de Vicente Manterola, El misterio de la Eucarística de Juan Vázquez de Mella, Tan...Tan ...poesía eucarística de P. Teodoro Palacios, La Institución de la Eucaristía según San Marcos, Los Santos Padres y la Eucaristía según San Mateo, cuentos como El niño de la guardia de Francisco Casañas Lemos y artículos históricos como La Eucaristía en los primeros siglos o Historia de los Congresos Eucarísticos, entre tantos otros.

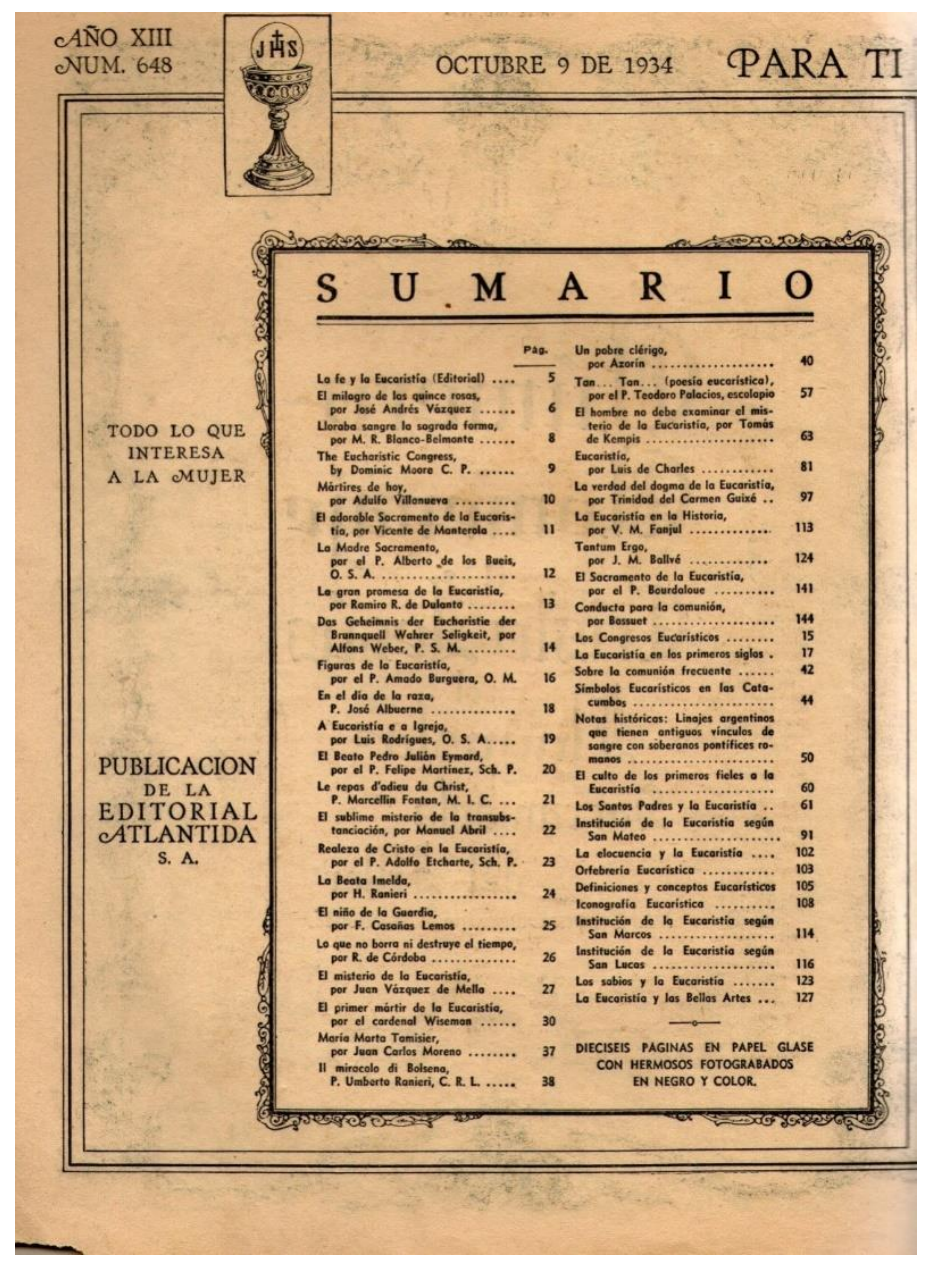

Sumario de la revista Para Ti con la totalidad de sus notas dedicadas a temas religiosos del Congreso Eucarístico Internacional. 
Igualmente, en esta ocasión se incluyeron textos, publicidades y un dossier fotográfico con dieciséis páginas brillantes referidas al Sacramento de la Eucaristía. Por otra parte, se les informaba a las lectoras que, dado que este número estaba dedicado al Augusto Sacramento de la Eucaristía, se suspendía en él la publicación de las novelas continuadas: Su Alteza Real y Odio y Amor, debido la temática y el lenguaje de las mismas. No obstante, además de las páginas dedicadas al inminente Congreso y de las secciones fijas, se incluyeron textos y publicidades como se lo hacía normalmente. ${ }^{17}$

En las secciones fijas como también las dedicadas a anuncios de página completa, se apelaba a la predisposición de la mujer para vivir el Congreso como un acontecimiento no solo religioso, sino también social. Sugerencias de vestimenta y telas adecuadas, confecciones de modistas especiales, venta y envío de objetos para las ceremonias (rosarios, misales, capas, mantillas) ocupaban buena parte del número. Bajo el título genérico de Imprescindibles se ofrecía vestimenta y calzado en anuncios de página completa, y cada producto llevaba la referencia de dónde y cómo adquirido; modalidad que publicaciones actuales mantienen en un formato renovado.

Indudablemente, la revista Para Ti supuso una innovación en el mercado por ser una publicación comercial sólo para mujeres, que combinaba coloridas carátulas, fotografías y publicidades con ficciones; tanto como correos de lectoras, lecciones morales y de comportamiento. A través de sus contenidos se proponía como un magazine de servicios multipropósitos y un manual de la vida cotidiana que pretendía abarcar todo el mundo de la mujer. Contaba, incluso, -además de las publicidades que por sí solas funcionaban como guías de compra y de consulta sobre las novedades y las tendencias- con un índice donde figuraban direcciones y teléfonos de utilidad para las mujeres.

En cierta manera, para la ideología de esta revista "ser mujer" era equivalente a velar por la apariencia física. ${ }^{18}$ Sus páginas dedicadas a la moda y al cuidado, procuraban orientar el interés femenino al presentar dibujos, formatos y bajadas discursivas que buscaban influir en el consumo, la imagen, la actitud ante la vida; lo que revestía un efecto consciente de la línea editorial para ayudar a forjar el carácter de la mujer según el rol social que ésta debía cumplir. En este sentido, ninguna de las páginas del Número Extraordinario se aleja de la lectora

\footnotetext{
${ }^{17}$ Revista Para Ti..., p.56.

${ }^{18}$ Bontempo, "Para Ti: una revista moderna...", pp. 127-156.
} 
tradicional ni del estereotipo de mujer que venimos analizando. Se fogueaba, entonces, el ámbito de lo femenino, lo adecuado para el consumo de vestimenta, artículos de tocador y belleza, y accesorios generales para el hogar. Este lugar de lo femenino no fue desplazado por el acontecimiento, antes bien, se veía reforzado desde el discurso y la oferta de consumo. Por dar un ejemplo, en la sección de "El Arte de Vestir, Corte y Costura", aparecía una capa elegante y apropiada para concurrir a los actos del Congreso Eucarístico, cuya descripción versaba: "Es una capa sencilla, rápida de confeccionar, así como de poco costo, y lo que es más interesante, se trata de la prenda más apropiada para llevar sobre cualquier vestido."

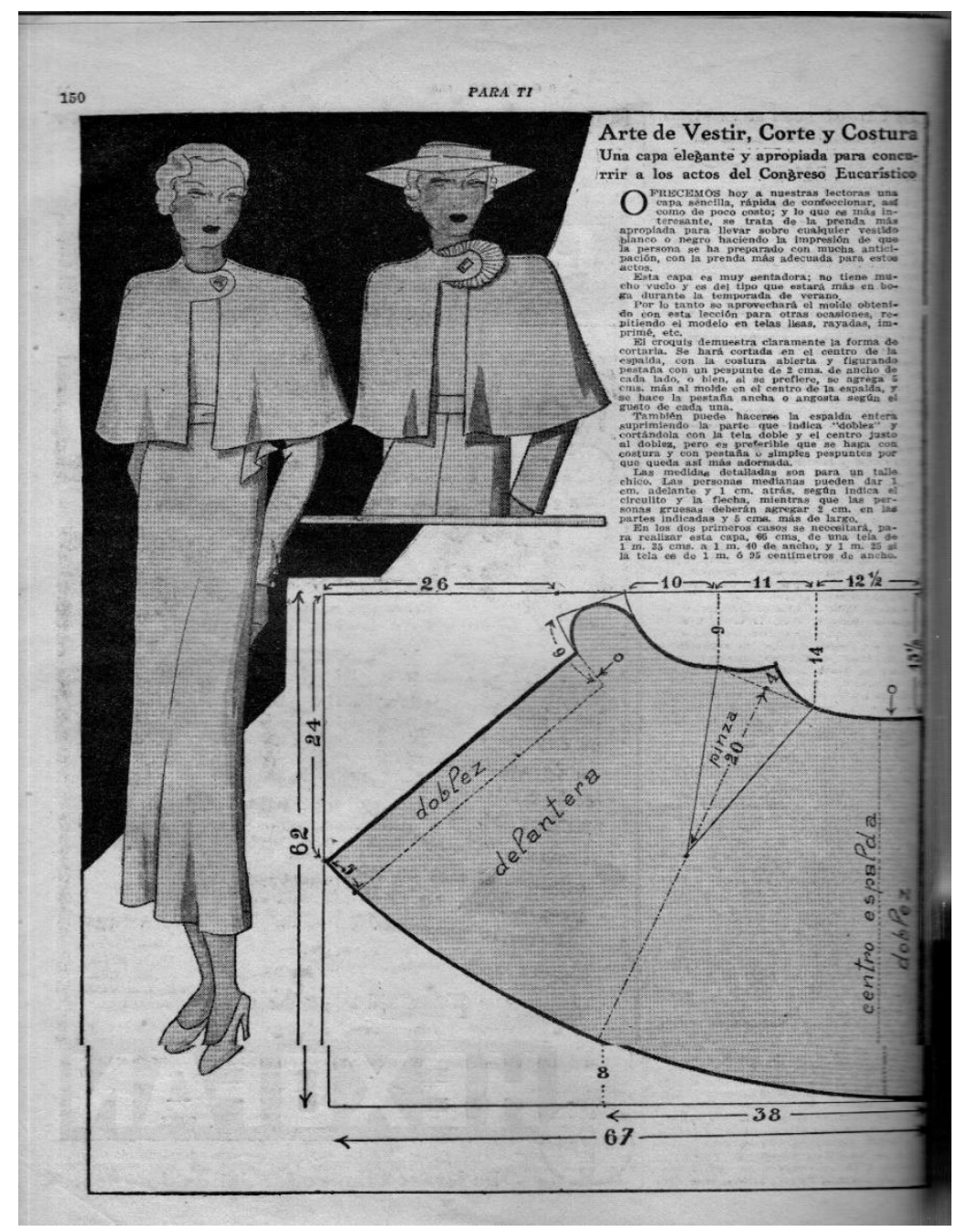

Una capa elegante y apropiada para concurrir a los actos del Congreso Eucarístico.

De igual forma, en las publicidades destinadas a la moda del congreso se observa un variopinto universo de consumidoras, con predominio de un sector de amas de casa de clase media urbana y de trabajadoras como empleadas, secretarias y maestras, entre otras. 


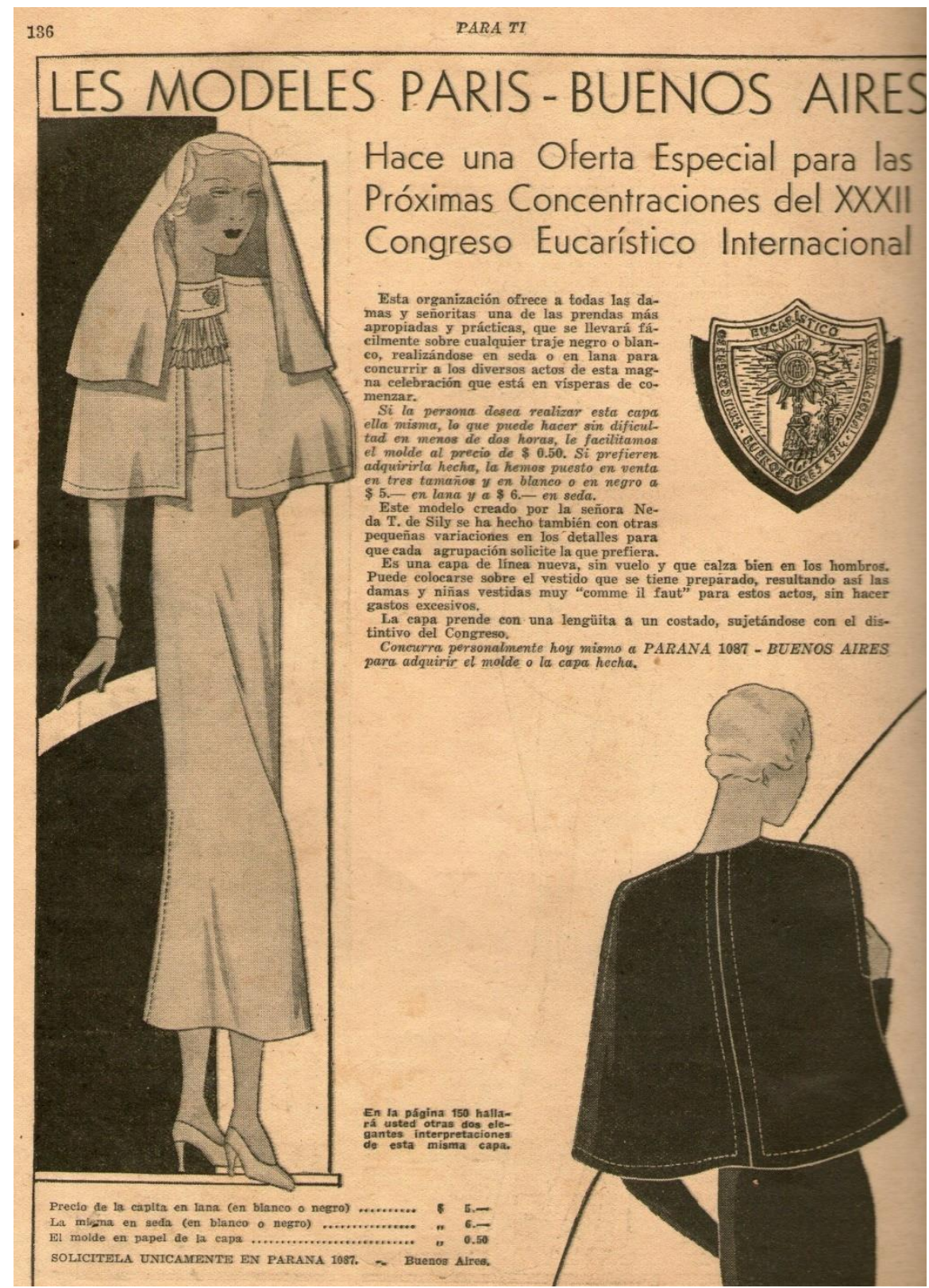

La elegancia que Para Ti pretendía para sus lectoras no distaba

del extraordinario acontecimiento que se estaba desarrollando por esos días en Buenos Aires.

Desde la aprobación de la ciudad de Buenos Aires como sede del Congreso, la revista comenzó a resaltar las características extraordinarias que tendría y los beneficios espirituales y temporales que reportaría su realización. Se llamaba, en consonancia, a toda la sociedad a trabajar con empeño por su organización y difusión y a participar activamente, pues era consabido que también se obtendrían bienes económicos de este gran suceso ya que se movilizarían capitales a partir de las variadas actividades a desarrollarse. Se sostenía, en suma, que la actividad económica se vería revitalizada a partir de la gran cantidad de peregrinos que llegarían a la ciudad y al país. 
En ese mismo sentido, en la edición especial de la revista aparecía una serie de publicidades que evidenciaban la importancia del acontecimiento en términos que poco tenían que ver con la dimensión espiritual. Allí se puede ver, además, el vínculo entre el destinatario femenino de la revista y la selección de productos a promocionar. La construcción discursiva de los avisos y del evento religioso, así pues, servirían de motivo para ampliar los productos ofertados a la mujer lectora de Para Ti. Por ejemplo, la empresa productora del té Sol invitaba a dejar contentos a los huéspedes que se recibieran con motivo del Congreso Eucarístico Internacional. Asimismo, la distribuidora de café La Puerto Rico apuntaba a los peregrinos para convocarlos a brindar a sus parientes y amigos un recuerdo sabroso de la estadía en Buenos Aires. También, a lo largo del ejemplar encontramos la oferta de otros artículos dedicados a recordar el Congreso, como las máquinas Kodak, rollos y álbumes fotográficos para perpetuar el evento, los banderines, las mayólicas y artículos varios; lo que reconfirma la idea consumista que hacía de este evento religioso una importante ventana para dicho fin. ${ }^{19}$ Otro botón de muestra de lo manifestado se observa en el tipo de publicidad que brindó la perfumería Dubarry, como vemos en la imagen:

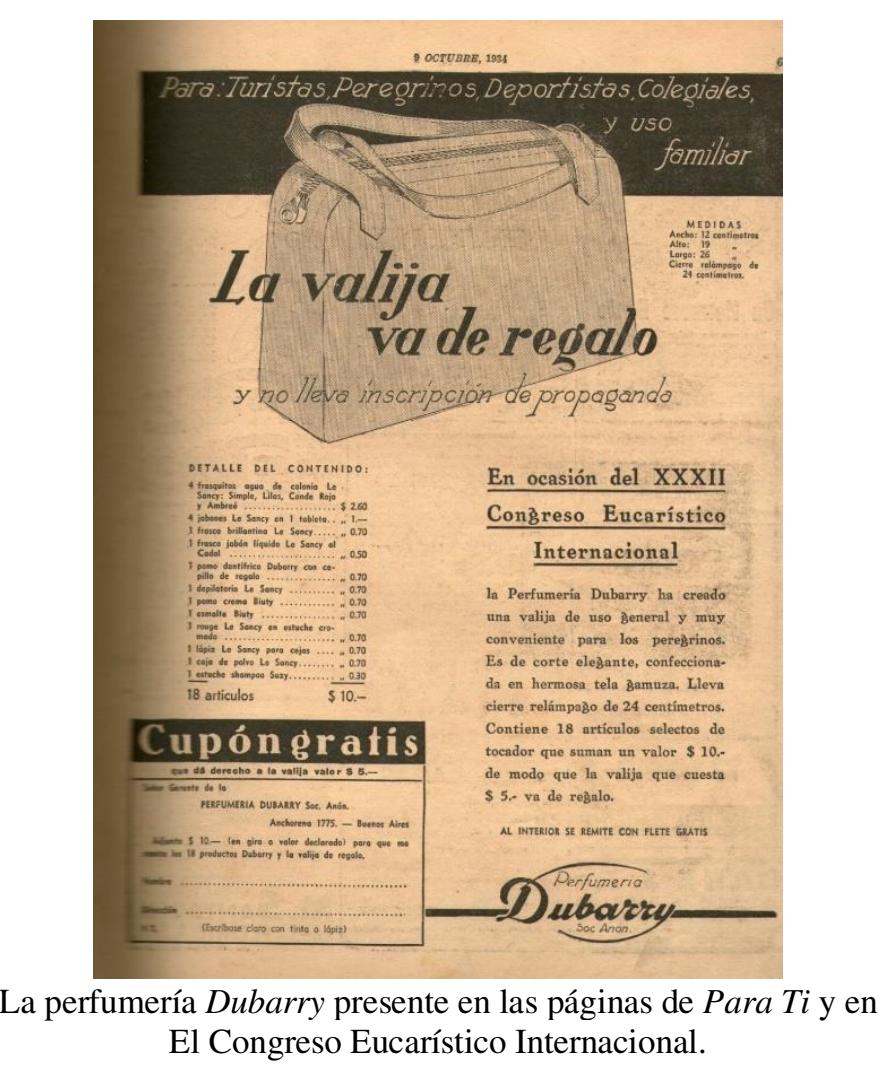

\footnotetext{
${ }^{19}$ Ver Revista Para Ti, Número homenaje a Cristo Jesús en el Augusto Sacramento del Altar. XXXII Congreso Eucarístico Internacional, $\mathrm{N}^{\circ}$ 648, 9 de octubre de (1934), también Olga Echeverría, "En busca de un orden jerárquico: los intentos de catolización de la década de 1930", Revista de Trabajo Social - FCH - UNCPBA, Año VI, No 10, diciembre de (2013), pp. 184-204.
} 
Es de destacar que tampoco quedó fuera de este impulso publicitario la propia Librería Atlántida ya que en honor a los festejos prontos a realizarse, se había adherido con el obsequio de una biblioteca de hierro forjado y martillado a mano. Se aclaraba que este valioso regalo se haría efectivo siempre que se adquiriese la Nueva Colección de Cuentos Vigil, ${ }^{20}$ dirigida a los niños y que contaba con un total de 50 volúmenes.

Por último, a pesar de ser un número en homenaje a Cristo sacramentado, se mantuvieron las ya mencionadas secciones fijas como Epistolario Sentimental, Consultorio Elegante, Secretos de Belleza, Nuevos Peinados, Mantelería, Labores, Para el Menú, ABC de las madres, Para las Dueñas de Casa, Páginas de las Novias, Bebés, Bordados...

\section{Algunas derivaciones del Congreso}

La Iglesia católica argentina había conseguido para mediados de la década del treinta un lugar de privilegio en la Plaza de Mayo para obtener la atención del público. Por aquellos tiempos, como efecto del quiebre económico y político en el espíritu ideológico se venía fortaleciendo la relación entre sociedad y fe. En esta línea debemos comprender la experiencia del catolicismo de masas, dentro de la cual el Congreso Eucarístico Internacional fue uno de los mayores exponentes.

Este acontecimiento tuvo tal repercusión que excedió con creces lo meramente religioso. No puede desconocerse, sin embargo, que una parte importante del mismo estuvo comprendido por múltiples actividades que se habían organizado en Buenos Aires, entre las que se incluía visitas a parroquias, hospitales y colegios, además de una innumerable cantidad de ceremonias. Asimismo, en estas circunstancias se impulsó la creación de los obispados de Rosario, Mendoza, Paraná, La Rioja, Azul, Viedma y Río Cuarto lo que contribuiría notablemente al fortalecimiento de la Iglesia.

Desde esta misma perspectiva, el fenómeno de masas que cristalizaría una década más tarde, comenzó a hacerse visible en torno a un evento que comprometía con fuerza la espiritualidad; uno de los pocos aspectos que, por los años treinta, podía movilizar. Más allá de algunos sucesos resonantes - como el sepelio de Carlos Gardel al año siguiente del Congreso-, la población civil sin distinciones de género y edad no ganaba las calles de las

\footnotetext{
${ }^{20}$ Editorial Atlántida publicó numerosos libros escritos por su propio fundador, Constancio C. Vigil, algunos de los cuales fueron grandes éxitos editoriales.
} 
ciudades de forma masiva ni cotidianamente. Coincidiendo con lo demostrado por Miranda Lida, el Congreso Eucarístico representó un "adelanto" de aquello que marcaría los tiempos por venir. ${ }^{21}$

Además, significó el comienzo de una época de esplendor del catolicismo argentino, a partir de la cual grandes figuras católicas del arte, las leyes, la política, el pensamiento, la dirigencia sindical y empresarial, descollarían en la vida social argentina. El catolicismo, entonces, se proponía como una tercera alternativa frente al liberalismo en decadencia y el comunismo en expansión, con un sesgo politizado, nacionalista, conservador, e hispanista.

Al mismo tiempo, el Congreso ponía en evidencia la fe y la religiosidad subterránea que permanecía en el imaginario y el comportamiento colectivo, eclipsado por el avance del Estado laico desde el siglo XIX. De acuerdo a este pensamiento, también contribuiría a la estrecha relación entre la Iglesia, Estado y sociedad civil, que se vería quebrada en las postrimerías del régimen peronista.

La ciudad de Buenos Aires se preparó adecuadamente para recibir a esos peregrinos que eran, también, turistas y se los reconocía no sólo por hablar lenguas diversas, sino también por la infaltable cámara fotográfica. Precisamente, ellos eran los ojos que registraban la ciudad para luego mostrarla al mundo. Buenos Aires, de este modo, llegaría a encumbrarse como una de las urbes más modernas de Sudamérica.

Otro elemento que tiñó de modernidad al evento fueron las transmisiones radiotelefónicas, los medios de transportes como trenes, aviones y barcos en contacto con el mundo, las iluminaciones en los edificios de las principales avenidas; tal es así que en las publicidades se comparaba a Buenos Aires con Paris, Londres, Roma y Madrid, las capitales de donde arribaba la mayoría de los visitantes europeos. Los atractivos que el viajero ponderaba, en general, no tenían mucho que ver con el carácter religioso del evento. En síntesis, el Congreso también constituía una carta de presentación, una forma de darse a conocer internacionalmente.

Por su parte, el semanario Para Ti, fomentó desde sus inicios la imagen femenina que ubicaba a la mujer en el flujo de las novedades de su tiempo con respecto a indumentaria, quehaceres, roles, consejos. Sus secciones definieron a las lectoras como una mujer de su tiempo, una mujer moderna que salía a conocer el mundo y había profesionalizado las tareas domésticas y la crianza de los hijos. Estas representaciones editoriales, además, iban

\footnotetext{
${ }^{21}$ Miranda Lida, "Mitos y verdades del XXXII Congreso Eucarístico Internacional, 75 años después", Criterio, $\mathrm{N}^{\mathrm{o}} 2354$ (2009), https://www.revistacriterio.com.ar/bloginst_new/2009/11/03/mitos-y-verdades-del-xxxiicongreso-eucaristico-internacional-75-anos-despues/
} 
acompañadas -como expusimos anteriormente- de publicidades que por sí solas funcionaban como guías de compra y de consulta sobre las novedades y tendencias del momento, con un índice donde figuraban direcciones y teléfonos de "utilidad" para ellas.

Siguiendo este hilo conductor en nuestro análisis sobre el número especial de la revista Para $T i$ resulta evidente que el Congreso Eucarístico significó un acontecimiento extraordinario para el cual la mujer debía estar adecuadamente vestida para la ocasión y con toda la elegancia posible. La apariencia física y el cuidado de la estética eran sus marcas de identidad y su presentación al mundo. Pues el mundo estaba en Buenos Aires por esos días.

Por lo demás, como en la revista era también muy importante el espacio que se le concedía a la publicidad (generalmente de marcas de ropa), a la hora de convocar para el evento religioso no sólo utilizó argumentos espirituales, sino que también apuntó a los beneficios económicos que movilizaría la llegada de multitud de peregrinos. La buena fe de sus intenciones, no dejan de lado oportunismos comerciales o beneficios de difusión. El consumo extraordinario que se viviría en esos pocos días de la jornada en completa ebullición se reflejó a lo largo de sus páginas.

Finalmente, en el número analizado del semanario es posible observar cómo se preparó a la mujer argentina para el trascendental evento religioso a realizarse en el país. Debía participar, entonces, como esa "mujer moderna" a la que se aludía desde la línea editorial. Atuendos y consejos recorren las páginas para que el rol femenino sea el acorde y esperado para estos acontecimientos.

\section{Fuentes Inéditas:}

Fondo Documental Dr. Elías Luque, donado al Instituto de Historia de la UCA por su hija Rosa Luque Viuda de Ponce, Rosario, 2004.

\section{Fuente Editas:}

"Carta Pastoral Colectiva de los Excmos. y Rvmos. Sres. Obispos Argentinos sobre el Congreso Eucarístico Internacional”, en Primer Congreso Eucarístico de la Diócesis de Santa Fe. Publicación Oficial de la Junta Diocesana de Santa Fe (Zona Sud), Rosario, 1933

Primer Congreso Eucarístico de la Diócesis de Santa Fe. Publicación Oficial de la Junta Diocesana de Santa Fe (Zona Sud), Rosario, 1933

Revista Mensual Lourdes, Año III, № 27, noviembre (1934). 
Revista Para Ti, "Número homenaje a Cristo Jesús en el Augusto Sacramento del Altar. XXXII Congreso Eucarístico Internacional”, No 648, 9 de octubre de (1934).

\section{Entrevista:}

Sra. Rosa Luque de Ponce, Rosario, 19 de mayo de 2004.

\section{Diarios y Periódicos:}

El Litoral, 10 al 15 de octubre de 1934, Año XVII, varios números.

El Orden, 12 y 14 deoctubre de 1934.

\section{Bibliográficas}

Adamovsky, Ezequiel. Historia de la clase media en Argentina. Apogeo y decadencia de una ilusión (1919-2003), Buenos Aires: Planeta, 2009.

Historia de las clases populares en Argentina. Desde 1880 a 2003, Buenos Aires: Sudamericana, 2012.

Alanís, Andrea Laura. "Prensa y mujer: nuevas páginas femeninas en los diarios La Nación y La Razón. Argentina, 1957-1963”. Tesis de posgrado, Universidad Nacional de Quilmes, Bernal, 2013.

Bavosi, Horacio Santiago. "Imaginarios sociales de vejez femenina presentes en discursos publicitarios de productos para el cuidado de la piel del rostro femenino en la revista argentina Para ti”. Tesis doctoral, Universidad Autónoma de Barcelona, España, setiembre 2019.

Bontempo, Paula. "Para Ti: una revista moderna para una mujer moderna, 1922-1935", ESTUDIOS SOCIALES, Universidad Nacional del Litoral, Vol.41, No1 (2011), pp. 127-156.

. “Editorial Atlántida. Un continente de publicaciones, 1918-1936”. Tesis doctoral, Universidad de San Andrés Buenos Aires, noviembre de 2012, pp. 292 y ss.

Chartier, Rogers. El mundo como representación. Historia cultural entre práctica y representación, Barcelona: Gedisa, 1992.

D’Andrea, Juana Alicia. “Todo lo que interesa a la mujer. Para Ti y su tono moralizador durante el primer gobierno peronista (1946-1952)", ponencia presentada en IV Congreso de Estudios sobre el peronismo, Facultad de Filosofía y Letras, Universidad Nacional de Tucumán, 2014. 
De Diego, José Luís. (Dir.). Editores y políticas editoriales en Argentina. 1880-2010, Buenos Aires: Fondo de Cultura Económica, 2014.

Echeverria, Olga. "En busca de un orden jerárquico: los intentos de catolización de la década de 1930", Revista de Trabajo Social - FCH - UNCPBA, No 10, diciembre (2013), pp. 184-204.

El Litoral. "Con un Acto de proporciones fantásticas se clausuraron las Asambleas del XXXII Congreso Eucarístico de Buenos Aires”, , 14 de octubre de 1934, , pág. 1.

Karush, Mathew. Cultura de Clase. Radio y cine en la creación de una Argentina dividida 1920-1946. Buenos Aires: Ariel, 2012.

Malosetti Costa, Laura y Gene, Marcela. Atrapados por la imagen. Arte y política e la cultura impresa argentina, Buenos Aires: Edhasa, 2013.

Mauro, Diego. "Multitudes católicas, sociedad de masas y política en la Argentina. Reflexiones a partir del Congreso Eucarístico Nacional de 1940”, Secuencia, № 97 , (enero-abril de 2017), pp. 200-231.

Miranda, Lida. "Mitos y verdades del XXXII Congreso Eucarístico Internacional, 75 años $\begin{array}{lllll}\text { después", } & \text { Criterio } & \text { Digital, } & N^{\circ} & 2354\end{array}$ https://www.revistacriterio.com.ar/bloginst_new/2009/11/03/mitos-y-verdades-del$\underline{\text { xxxii-congreso-eucaristico-internacional-75-anos-despues/ }}$ . Historia del Catolicismo en Argentina. Entre el siglo XIX y XX, Buenos Aires: Siglo XXI, 2015.

Rodríguez Lago, José Ramón. "La clave Cortesi. La política vaticana en la República Argentina (1926-1936)", Historia contemporánea, Universidad de Vigo, España, $N^{\circ}$ 55 (2017), pp. 517-546.

Rogers, Geraldine. Caras y Caretas. Cultura, política y espectáculo en los inicios del siglo XX argentino, Buenos Aires: ENLP, 2008.

Sarlo, Beatriz. El imperio de los sentimientos. Narraciones de circulación periódica en la Argentina, Buenos Aires: Siglo XXI, 2011.

Scampini, Jorge A. "La Eucaristía, primicia y fundamento de un orden social verdaderamente justo: un aporte con ocasión del Congreso Eucarístico Nacional”, Revista Teología, , Tomo LIII, No 119 (2016).

Serrano, Silvia. "La revista Para Ti: Configuraciones de identidades femeninas". Tesis de grado, Universidad Nacional de La Plata, Facultad de Humanidades y Ciencias de la Educación, http://www.memoria.fahce.unlp.edu.ar/tesis/te.867/te.867.pdf 
Ulanovsky, Carlos. Paren las rotativas. Diarios, revistas y periodistas 1920-1969, Buenos Aires: Emecé, 2005.

\section{Imágenes y Láminas}

Historia de Parroquias de Buenos Aires (Comisión de Investigaciones Histórico Eclesiásticas del Arzobispado de Buenos Aires www.historiaparroquias.com.ar). 